\title{
ÁRBOL FILOGENÉTICO Y DIVERSIDAD DE BACTERIAS ENDÓFITAS ASOCIADAS A Theobroma cacao L. EN UNA ZONA DE LA PROVINCIA DE ESMERALDAS, ECUADOR
}

\author{
María A. Vera-Loor ${ }^{1}$, Alexander Bernal-Cabrera ${ }^{2}$, Danilo Vera-Coello ${ }^{1}$, Michel Leiva- Mora ${ }^{3}$, \\ Alan Rivero-Aragón ${ }^{4}$ y Lisbeth Morales-Díaz de V. ${ }^{4}$
}

\begin{abstract}
RESUMEN
Dada la importancia que tendría el uso de bacterias endófitas para el control de las enfermedades del cacao, el objetivo de este estudio fue construir el árbol filogenético y caracterizar las bacterias endofíticas formadoras de endosporas en función de la altitud, la edad y el tejido de la planta de cacao en una zona productora de la provincia de Esmeraldas en Ecuador. El aislamiento de las bacterias se realizó a partir de secciones de tejidos de mazorcas y pedicelos de la flor en cultivares de cacao Criollo tipo Nacional. Se obtuvieron 45 aislados de bacterias endófitas formadoras de endosporas, asociados principalmente con tejidos del endocarpio. El árbol filogenético reveló que todas las bacterias pertenecen al género Bacillus. No se encontró relación entre el número de aislados bacterianos con la edad de la planta, aunque hubo una ligera tendencia a la disminución de los aislados hacia los sitios de mayor altitud.

Palabras clave adicionales: Bacillus, biocontrol, cacao, endocarpio, pedicelo de flores
\end{abstract}

\section{ABSTRACT \\ Phylogenetic tree and diversity of endophytic bacteria associated with Theobroma cacao L. in a zone of Esmeraldas Province, Ecuador}

Given the importance of using endophytic bacteria for the control of cocoa diseases, the objective of this study was to build the phylogenetic tree and characterize the endophytic endospore-forming bacteria according to their cropping altitude, age and tissue of the cocoa plant in a producing area of the Esmeraldas province, in Ecuador. The isolation of bacteria was done from healthy pods and flower pedicels from cocoa Criollo Type Nacional cultivar. Forty-five endospore forming endophytic bacteria were recovered, mainly from the endocarp tissue. The phylogenetic tree showed that all bacteria belong to the genus Bacillus. No association was found between the number of bacterial isolates and the age of the plant, although there was a slight tendency for the isolates to decrease towards the higher altitude sites.

Additional keywords: Bacillus, biocontrol, cocoa, endocarp, flower pedicel

\section{INTRODUCCIÓN}

El uso de bacterias endófitas para el control de las enfermedades del cacao es incipiente; sin embargo, dados los resultados interesantes presentados en los pocos documentos disponibles, ciertamente merece mayor atención debido a que pueden ayudar a conservar la estabilidad $y$

Recibido: Enero 4, 2021

Aceptado: Mayo 13, 2021

${ }^{1}$ Estación Experimental Tropical Pichilingue, Instituto Nacional de Investigaciones Agropecuarias. Los Ríos, Ecuador, CP: 120224. e-mail: mariverloor2007@gmail.com; danilo.vera@ iniap.gob.ec

${ }^{2}$ Dpto. de Agronomía. Facultad de Ciencias Agropecuarias. Universidad Central "Marta Abreu” de las Villas.

CP: 54830. e-mail: alexanderbc@uclv.edu.cu (autor de correspondencia)

${ }^{3}$ Facultad de Ciencias Agropecuarias, Universidad Técnica de Ambato, Cevallos, Tungurahua, Ecuador.

e-mail: leivamoramichelcelin@gmail.com

${ }^{4}$ Dpto. de Biología. Facultad de Ciencias Agropecuarias. Universidad Central "Marta Abreu" de las Villas. Villa Clara, Cuba, CP: 54830. e-mail: alanra@uclv.edu.cu; lisbeth@uclv.cu 
diversidad de las comunidades agrícolas, reducir el uso de insumos químicos y ayudar a los agricultores a adaptarse a un mundo en rápido cambio donde la intensificación agrícola, el uso de la tierra y el cambio climático aumentan el riesgo de epifitias devastadoras (Ek-Ramos et al., 2019).

Melnick et al. (2011) en un estudio sobre el uso de bacterias endófitas formadoras de endosporas para el control de enfermedades de cacao, encontraron que en este árbol pueden coexistir múltiples especies de bacterias formadoras de endosporas. Algunas de ellas exhibieron antagonismo contra los tres agentes patógenos principales del cacao, Phytophthora spp., Moniliophthora roreri y M. perniciosa.

Ouattara et al. (2019) demostraron la importancia de seleccionar bacterias endófitas nativas de seis regiones productoras de cacao en Costa de Marfil para realizar estudios in vitro y en invernadero para discriminar los aislados con mayor capacidad de solubilización de fosfatos y proponerlas como posibles candidatas a desarrollar formulaciones que puedan promover el crecimiento y desarrollo de diferentes variedades de plantas de cacao.

Teniendo en cuenta que solo una pequeña parte de la diversidad microbiana asociada a los tejidos del árbol de cacao ha sido descrita y caracterizada, y dada la importancia de este cultivo en la agricultura del Ecuador (Moreno et al., 2020), el objetivo del presente trabajo fue crear el árbol genético y caracterizar las bacterias endofíticas formadoras de endosporas en función de la altitud, la edad y el tejido de la planta de cacao en una zona productora de la provincia de Esmeraldas en Ecuador.

\section{MATERIALES Y MÉTODOS}

Se realizaron prospecciones de las potenciales bacterias endófitas en fincas de producción de cacao, con plantas de diferentes edades, ubicadas en diversas parroquias del cantón Quinindé, provincia de Esmeraldas, Ecuador (Cuadro 1). Las plantas correspondían al cultivar de cacao Criollo tipo Nacional (autóctono de Ecuador), que no había sido sometido a la aplicación de fungicidas. En cada finca se colectaron cojines florales y mazorcas, sin síntomas aparentes de moniliasis, mediante muestreos realizados al azar.

Las muestras se trasladaron al laboratorio de Fitopatología del Departamento de Protección Vegetal de la Estación Experimental Tropical Pichilingue perteneciente al Instituto Nacional de Investigaciones Agropecuarias (INIAP), para ser procesadas antes de las $4 \mathrm{~h}$ de haber sido tomadas, tal como lo sugerido por Melnick et al. (2011).

Las mazorcas y pedicelos florales fueron sometidas a un proceso de lavado con agua corriente y detergente. Posteriormente, se realizaron los cortes de secciones de tejidos sanos del mesocarpio y endocarpio de las mazorcas, así como secciones de tejido del pedicelo de los cojines florales. Luego, bajo cámara de flujo laminar se procedió a la desinfección de los tejidos con hipoclorito de sodio, seguido con alcohol y un lavado con agua estéril. Las muestras se colocaron sobre papel absorbente estéril y se dejaron secar.

Cuadro 1. Descripción de los sitios de colecta en el cantón Quinindé, provincia de Esmeraldas

\begin{tabular}{clcccc}
\hline Parroquia & $\begin{array}{c}\text { Propietario } \\
\text { de la finca }\end{array}$ & Latitud & Longitud & $\begin{array}{c}\text { Altitud } \\
\text { (msnm) }\end{array}$ & $\begin{array}{c}\text { Edad del cultivo } \\
\text { (años) }\end{array}$ \\
\hline \multirow{3}{*}{ Malimpia } & Sra. Solis & $0^{\circ} 67^{\prime} 45^{\prime \prime} \mathrm{N}$ & $79^{\circ} 49^{\prime} 44^{\prime \prime} \mathrm{W}$ & 95 & 13 \\
& Sr. German & $0^{\circ} 67^{\prime} 55^{\prime \prime} \mathrm{N}$ & $79^{\circ} 48^{\prime} 56^{\prime \prime} \mathrm{W}$ & 98 & 12 \\
& Sr. Alcivas & $0^{\circ} 67^{\prime} 56^{\prime \prime} \mathrm{N}$ & $79^{\circ} 48^{\prime} 23^{\prime \prime} \mathrm{W}$ & 98 & 2 \\
& & & & & 13 \\
\multirow{5}{*}{ Rosa Zarate } & Sr. Gómez & $0^{\circ} 18^{\prime} 35^{\prime \prime} \mathrm{N}$ & $79^{\circ} 24^{\prime} 57^{\prime \prime} \mathrm{W}$ & 123 & 14 \\
& Sr. Quintana & $0^{\circ} 18^{\prime} 49^{\prime \prime} \mathrm{N}$ & $79^{\circ} 25^{\prime} 32^{\prime \prime} \mathrm{W}$ & 118 & 35 \\
& Sr. Brizeño & $0^{\circ} 19^{\prime} 29^{\prime \prime} \mathrm{N}$ & $79^{\circ} 26^{\prime} 23^{\prime \prime} \mathrm{W}$ & 116 & \\
& & & & & \\
\multirow{2}{*}{ La Unión } & & $0^{\circ} 07^{\prime} 44^{\prime \prime} \mathrm{N}$ & $79^{\circ} 24^{\prime} 02^{\prime \prime} \mathrm{W}$ & 193 & 40 \\
& Sra. Díaz & $0^{\circ} 08^{\prime} 04^{\prime \prime} \mathrm{N}$ & $79^{\circ} 23^{\prime} 04^{\prime \prime} \mathrm{W}$ & 181 & 5 \\
& Sr. Cunalata & $0^{\circ} 13^{\prime} 38^{\prime \prime} \mathrm{N}$ & $79^{\circ} 24^{\prime} 46^{\prime \prime} \mathrm{W}$ & 154 & 10 \\
\hline
\end{tabular}


Para el aislamiento de las bacterias formadoras de endosporas se tomaron los tejidos previamente desinfectados y se colocaron en tubos de ensayo con tampón fosfato de potasio estéril 0,1 M (pH 7) e incubaron a $75{ }^{\circ} \mathrm{C}$ en baño termostático (baño María) durante $15 \mathrm{~min}$. Luego se procedió a la trituración de los tejidos y siembra en medio de cultivo agar triptona soya (TSA) por el método de diseminación con la ayuda de una espátula metálica estéril. Las colonias que presentaron características macroscópicas diferentes, se subcultivaron independientemente en medio de cultivo TSA e incubaron a $28{ }^{\circ} \mathrm{C}$ por 24 h hasta su posterior verificación de crecimiento.

La verificación de la presencia de bacterias con endosporas se realizó sembrando las bacterias en tubos de ensayo con $5 \mathrm{~mL}$ de medio de cultivo caldo triptona soya (TSB) e incubadas a $28{ }^{\circ} \mathrm{C}$ por 3 días. Seguidamente, los cultivos se incubaron a $75{ }^{\circ} \mathrm{C}$ durante $15 \mathrm{~min}$. Finalmente, los cultivos bacterianos se extendieron en placas de Petri con medio de cultivo TSA bajo condiciones de incubación de $28{ }^{\circ} \mathrm{C}$ por $24 \mathrm{~h}$ hasta observar crecimiento bacteriano.

Para la identificación molecular de las cepas bacterianas se siguió el proceso descrito por Vera et al. (2020) empleando la secuenciación del ARNr 16S. Las filogenias se construyeron mediante el método de vecino más cercano (Saitou y Nei, 1987) y con una máxima verosimilitud implementado en MEGA 7 (Kumar et al., 2016); los valores ubicados en los diferentes clados y nodos fueron mayores al $50 \%$.

Para establecer relación entre la frecuencia de los aislados bacterianos con la altitud y edad del cultivo se utilizó un análisis de regresión mediante el empleo del programa Statistix v.8.

\section{RESULTADOS Y DISCUSIÓN}

Se obtuvieron 45 aislados bacterianos asociados a los tejidos vegetales muestreados. La mayoría de ellos $(55,5 \%)$ procedieron del endocarpio, algunos del mesocarpio $(26,7 \%)$ y sólo unos pocos $(17,8 \%)$ del pedicelo de la flor. No se encontró asociación $(P>0,05)$ entre la presencia de aislados bacterianos y la edad de la planta (Figura 1) o la altitud de la finca (Figura 2), aunque hubo una ligera tendencia a la disminución de los aislados hacia los sitios de mayor elevación.

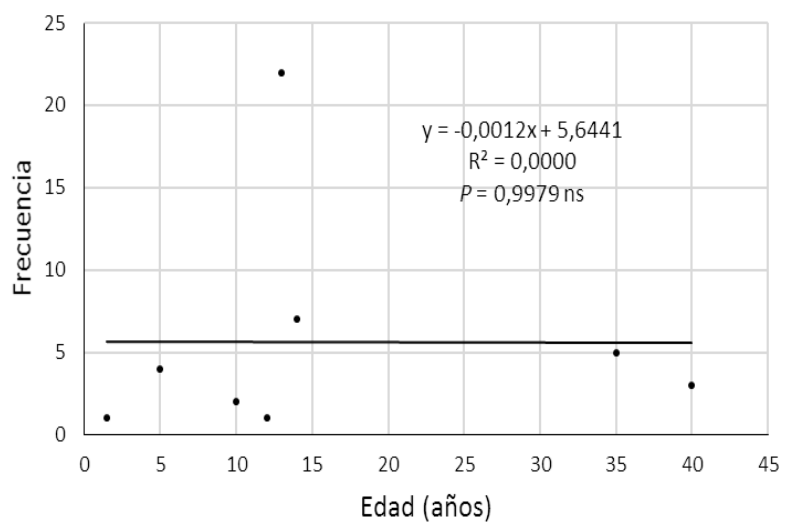

Figura 1. Frecuencia de obtención de aislados bacterianos en relación a la edad de la planta. ns: no significativo $(P>0,05)$

El tratamiento térmico, utilizado para obtener los aislados bacterianos, eliminó todas las bacterias que no produjeron endosporas $y$ probablemente la mayoría de los géneros bacterianos, incluyendo bacterias formadoras de endosporas que estaban creciendo en una etapa vegetativa en el momento del muestreo. De forma semejante, Földes et al. (2000) consideraron muy apropiadas estas técnicas de aislamiento del género Bacillus donde es importante caracterizar la termorresistencia de las endosporas bacterianas pues éstas le pueden garantizar mayor persistencia a las bacterias en los tejidos vegetales, lo cual es una condición necesaria para seleccionar candidatos promisorios para el control biológico de agentes fitopatógenos.

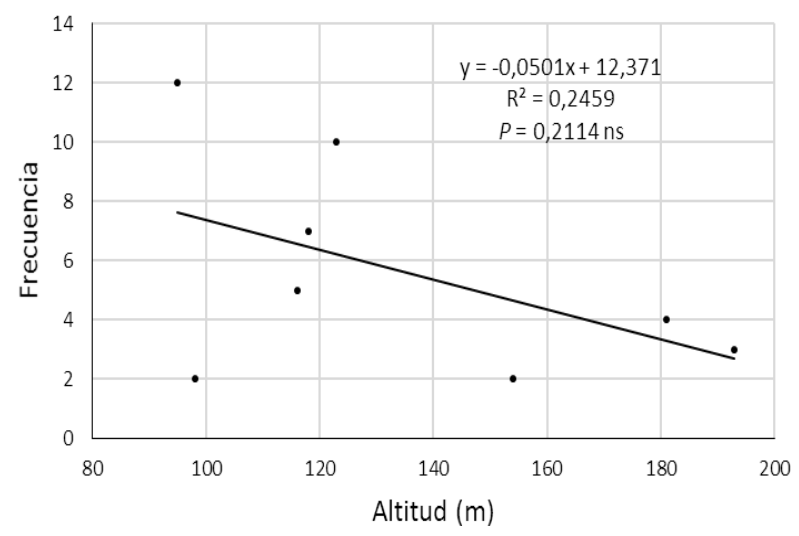

Figura 2. Frecuencia de obtención de aislados bacterianos en relación con la altitud de la zona. ns: no significativo $(\mathrm{P}>0,05)$

De los aislados obtenidos, la mayoría fueron del endocarpio de la mazorca del cacao. Este 
hallazgo pudiera explicarse por la interrelación entre la flor y el fruto; así como la composición química del mucílago del cacao, el cual posee un alto contenido de agua y es rico en azúcares, proteínas y pectinas (Vallejo et al., 2016), sustancias que conforman un medio favorable para la multiplicación de bacterias.

Por otro lado, este resultado no concuerda con lo señalado por Hallmann (2001) quien planteó que los endófitos bacterianos son colonizadores poco abundantes en los tejidos de flores, frutos y semillas de diferentes especies de plantas, señalando que en condiciones naturales, la mayoría de las flores y frutos no contienen bacterias endófitas o solo pueden alcanzar densidades de población muy bajas $\left(10^{2}-10^{3}\right.$ UFC $\mathrm{g}^{-1}$ de masa fresca de tejido vegetal).

En un estudio similar al presente, Melnick et al. (2011) obtuvieron 69 aislados de bacterias endófitas formadoras de endosporas a partir de los tejidos de hojas, ramas, cojines florales y mazorca de una colección de clones de $T$. cacao tipo Nacional procedente del programa de mejoramiento genético del cultivo, con fines de emplearlos en el control biológico de los principales hongos patógenos que afectan la mazorca. Sin embargo, estos autores no analizaron el aislamiento de bacterias endófitas procedentes de secciones de tejido de mazorcas de cacao en diferentes fases de desarrollo. En este trabajo, detectamos la mayor cantidad de bacterias en los frutos más jóvenes, resultado que debe tener relación con el grosor de la epidermis, la cual se encuentra menos esclerotizada en los frutos de menor edad y facilita una mejor colonización por las bacterias. Además, si se toma en cuenta que las mazorcas de cacao son más susceptibles a $M$. roreri en los tres primeros meses de desarrollo, este resultado aseguraría una mayor probabilidad de protección del fruto contra este hongo fitopatógeno.

Además, se conoce que en el cacao habita una gran diversidad de hongos endófitos (Bae et al., 2009; Hanada et al., 2010) que coexisten con las bacterias. El cacao es el hábitat de una comunidad microbiana diversa que todavía está parcialmente caracterizada, de la cual se podrían obtener agentes de control biológico, particularmente bacterias endófitas formadoras de endosporas.
Estas estructuras de resistencia son el principal ingrediente activo de los formulados comerciales, y le confieren mayor viabilidad y capacidad de resistencia a factores bióticos y abióticos estresantes. El árbol filogenético construido con secuencias del gen 16S rRNA de las cepas aisladas del cacao (Figura 3) reveló que todas pertenecen al género Bacillus.

Es de destacar; sin embargo, que a pesar de que el marcador $\mathrm{ADNr} 16 \mathrm{~S}$ empleado en esta investigación, es el marcador molecular más utilizado para la clasificación de organismos procariotas por sus características deseables (Schleifer, 2009), las bacterias del género Bacillus comprenden actualmente más de 336 especies, por lo que la clasificación basada en un gen único probablemente tiene bajo poder de resolución a este nivel (LPSN, 2016).

Este estudio contribuyó a un mejor conocimiento del microbioma del cacao a partir de la colecta de muestras de frutos del cultivar Criollo tipo Nacional, de donde se extrae el "Cacao Arriba", de fino aroma y sabor con calidad gourmet, que coloca al país como el primer exportador de este tipo de cacao; además de confirmar la presencia de este microbioma en los tejidos de los órganos reproductivos (flores y mazorcas) del cultivo.

\section{CONCLUSIONES}

Se caracterizaron cepas endófitas de Bacillus spp. asociadas con frutos y pedicelos florales de $T$. cacao. Estas bacterias pudieran ser empleadas como agentes de control biológico de Moniliophthora roreri, una de las principales enfermedades fúngicas que limitan la producción en zonas cacaoteras de la provincia de Esmeraldas, Ecuador.

\section{LITERATURA CITADA}

1. Bae, H., R.C. Sicher, M.S. Kim, S.H. Kim, M.D. Strem, R. Melnick y B.A. Bailey. 2009. The beneficial endophyte Trichoderma hamatum isolate DIS $219 \mathrm{~b}$ promotes growth and delays the onset of the drought response in Theobroma cacao. Journal of Experimental Botany 60(11): 3279-3295. 


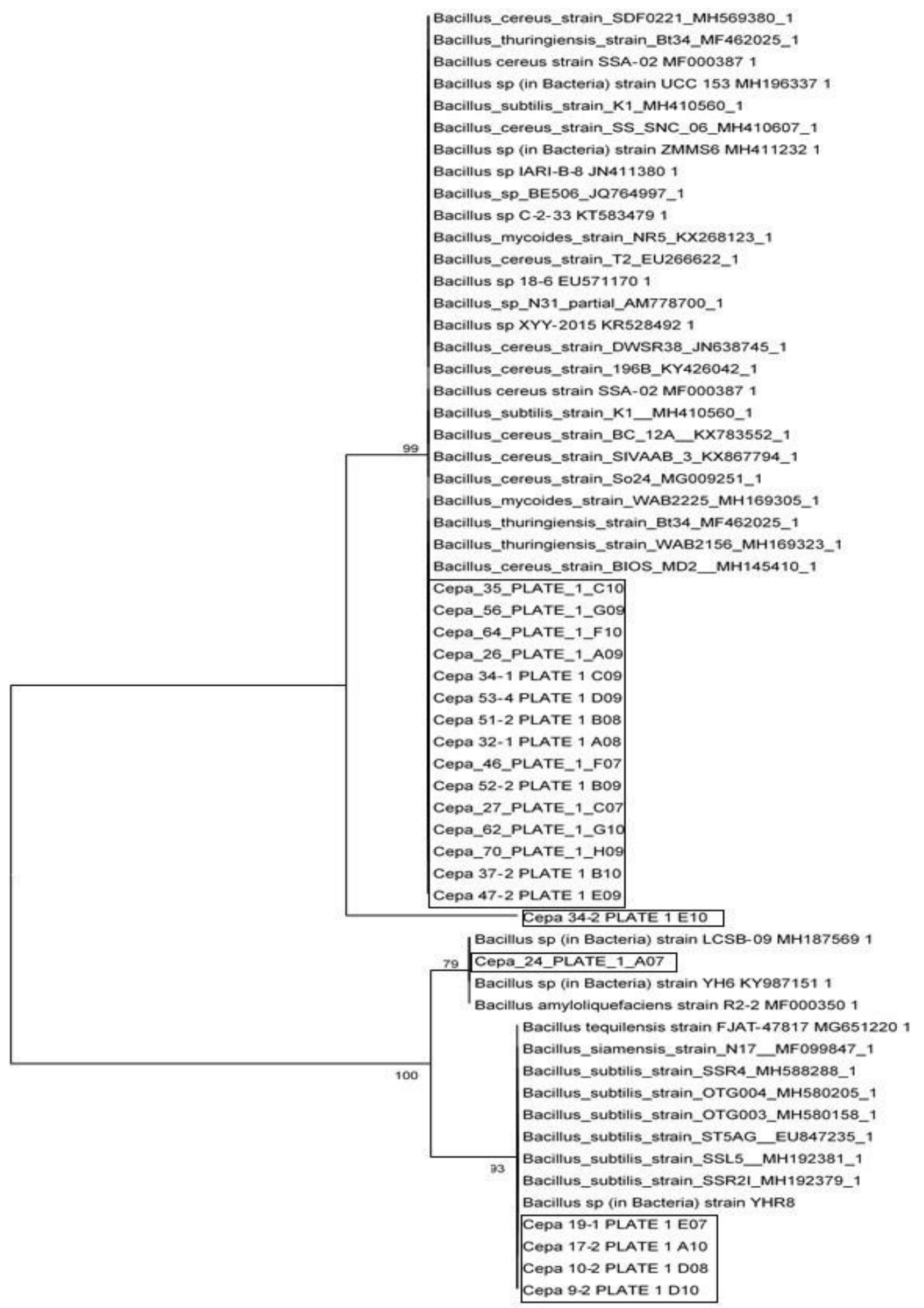

Figura 3. Árbol filogenético de máxima probabilidad, basado en la secuencia de los genes $16 \mathrm{~S} \mathrm{ARNr}$, que muestra la relación entre las cepas endófitas de Bacillus aisladas de Theobroma cacao. Árbol construido por el método de máxima probabilidad en Mega 7. Valores de Bootstrap $\geq 50$ (basado en 1000 réplicas) para cada nodo

2. Ek-Ramos, M., R. Gómez-Flores, A. Bioactive products from plant-endophytic Orozco-Flores, C. Rodríguez-Padilla, G. gram-positive bacteria. Frontier in González-Ochoa y P. Tamez-Guerra. 2019. Microbiology 10: 463. 
3. Földes, T., I. Banhegyi, Z. Herpai, L. Varga y J. Szigeti. 2000. Isolation of Bacillus strains from the rhizosphere of cereals and in vitro screening for antagonism against phytopathogenic, food borne pathogenic and spoilage microorganisms. Journal of Applied Microbiology 89(5): 840-846.

4. Hallmann, J. 2001. Plant interactions with endophytic bacteria. In: CABI Publishing, New York. pp. 87-119.

5. Hanada, R., A. Pomella, H. Costa, J. Bezerra,L. Loguercio y J. Pereira. 2010. Endophytic fungal diversity in Theobroma cacao (cacao) and T. grandiflorum (cupuaçu) trees and their potential for growth promotion and biocontrol of black-pod disease. Fungal Biology 114(11-12): 901-910.

6. Kumar, S., G. Stecher y K. Tamura. 2016. MEGA 7: Molecular Evolutionary Genetics Analysis version 7.0 for bigger datasets. Molecular Biology and Evolution 33(7): 18701874.

7. LPSN (List of Prokaryotic names with Standing in Nomenclature). 2016. Genus Bacillus. Microbiology Society. Charles Darwin House, 12 Roger St, London WC1N 2JU, United Kingdom. https://n9.cl/imk4y (consulta de mayo 13, 2020).

8. Melnick, R., C. Suárez, B. Bailey y P. Backman. 2011. Isolation of endophytic endospore-forming bacteria from Theobroma cacao as potential biological control agents of cacao diseases. Biological Control 57(3): 236-245.
9. Moreno-Miranda, C., I. Molina, Z. Miranda, R. Moreno y P. Moreno. 2020. La cadena de valor de cacao en Ecuador: Una propuesta de estrategias para coadyuvar a la sostenibilidad. Bioagro 32(3): 205-214.

10. Ouattara, A., K. Coulibaly, I. Konate, B. Ismaë, A. Tidou y A. Filali-Maltouf. 2019. Selection of cocoa tree (Theobroma cacao Linn) endophytic bacteria solubilizing tricalcium phosphate, isolated from seedlings grown on soils of six producing regions of Côte d'Ivoire. Advances in Microbiology 9(9): 842-852.

11.Saitou, N. y M. Nei. 1987. The neighborjoining method: a new method for reconstructing phylogenetic trees. Molecular biology and evolution 4(4): 406-425.

12.Schleifer, K.H. 2009. Classification of Bacteria and Archaea: past, present and future. Systematic and Applied Microbiology 32(8): 533-542.

13. Vallejo-Torres, C.A., R. Díaz-Ocampo, W. Morales-Rodríguez, R. Soria-Velasco, J.F. Vera-Chang y C. Baren-Cedeño. 2016. Utilización del mucílago de cacao, tipo nacional y trinitario, en la obtención de jalea. Espamciencia 7(1): 51-58.

14.Vera-Loor, M.A., A. Bernal-Cabrera, D. VeraCoello, M. Leiva Mora y L. Morales- Díaz de Villegas. 2020. Identificación de bacterias endófitas formadoras de endosporas asociadas a Theobroma cacao L. en Quinindé, Esmeraldas, Ecuador. Revista Centro Agrícola 47 (Número Especial): 63-67. 